\title{
Generalised and abdominal obesity and risk of diabetes, hypertension and hypertension-diabetes co-morbidity in England
}

\author{
Vasant Hirani* , Paola Zaninotto and Paola Primatesta \\ Department of Epidemiology and Public Health, Royal Free and University College London Medical School, \\ University College London, 1-19 Torrington Place, London WC1E 6BT, UK
}

Submitted 1 February 2007: Accepted 25 May 2007: First published online 4 September 2007

\begin{abstract}
Objectives: To look at trends in generalised (body mass index (BMI) $\geq 30 \mathrm{~kg} \mathrm{~m}^{-2}$ ) and abdominal (waist circumference (WC) $>102 \mathrm{~cm}$ in men, $>88 \mathrm{~cm}$ in women) obesity among adults between 1993 and 2003, and to evaluate their association with diabetes, hypertension and hypertension-diabetes co-morbidity (HDC) in England.

Design: Analyses of nationally representative cross-sectional population surveys, the Health Survey for England (HSE).

Subjects: Non-institutionalised men and women aged $\geq 35$ years.

Measurements: Interviewer-administered questionnaire (sociodemographic information, risk factors, doctor-diagnosed diabetes), measurements of height and weight to calculate BMI. WC and blood pressure measurements were taken by trained nurses.

Results: Generalised obesity increased among men from $15.8 \%$ in 1993 to $26.3 \%$ in 2003 , and among women from $19.3 \%$ to $25.8 \%$. Abdominal obesity also increased in both sexes (men: $26.2 \%$ in 1993 to $39.0 \%$ in 2003; women: $32.4 \%$ to $47.0 \%$ ). In 1994, 1998 and 2003, generalised and abdominal obesity were independently associated with risk of hypertension, diabetes and HDC. The odds of diabetes associated with generalised obesity in 1994, 1998 and 2003 were 1.62, 2.26 and 2.62 , respectively, in women and 1.24, 1.82 and 2.10, respectively, in men. Similar differences were observed for hypertension and HDC. Men and women with abdominal obesity also showed a higher risk for diabetes, hypertension and HDC than those with a normal WC.

Conclusions: If current trends in obesity continue then the risk of related morbidities may also increase. This will impact on cardiovascular disease morbidity and mortality, with cost implications for the health service. Therefore there is an urgent need to control the epidemic of obesity.
\end{abstract}

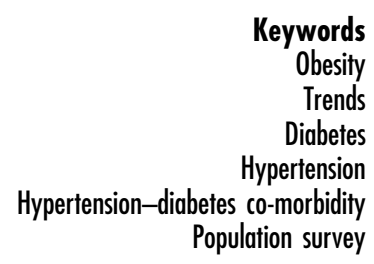

The prevalence of obesity is increasing rapidly worldwide $^{1}$ and in England ${ }^{2}$. According to national data, more than half of all adults are currently classified as overweight or obese ${ }^{3}$. Obesity can reduce overall quality of life and lead to premature death ${ }^{4}$ due to its association with serious interrelated conditions, such as type 2 diabetes and hypertension ${ }^{5-7}$, that strongly increase the risk of cardiovascular disease $(\mathrm{CVD})^{8-10}$.

The most commonly used anthropometric index of obesity is body mass index (BMI), calculated as weight $(\mathrm{kg})$ divided by the square of height $\left(\mathrm{m}^{2}\right)$. However, BMI alone is not a good predictor of risk for many cardiovascular disorders ${ }^{11}$ since the adverse health consequences associated with obesity are related to increased adiposity rather than an increase in weight alone $^{12}$.

It has been recognised that abdominal obesity is one of the key constituents of the metabolic syndrome ${ }^{13}$, a strong predictor of type 2 diabetes and/or $\mathrm{CVD}^{14}$. The International Obesity Task Force (IOTF) ${ }^{15}$ has emphasised that the health burden of obesity would be more easily predicted if the hazards of accumulating intraabdominal fat were also monitored in addition to BMI by simple measures such as waist circumference (WC).

In order to look at the effect of the observed obesity trends, we performed an analysis of cross-sectional data from 1993 to 2003. Although cross-sectional data cannot be relied upon to provide information vis-à-vis the 
causality of an association, we speculate that the effects of the increasing trends in both generalised and central obesity in England are likely to potentially increase the risk for related co-morbidities such as type 2 diabetes, hypertension and hypertension-diabetes co-morbidity (HDC).

Because of insufficient sample size, many studies are restricted to either hypertension or diabetes, or individual factors associated with CVD, and there are limited studies that have looked at the impact of generalised and central obesity on the risk of the interrelated metabolic disorder HDC (i.e. the existence of both diabetes and hypertension).

The aims of the present study were to use data from the Health Survey for England (HSE) to look at the effect of increasing trends in generalised and abdominal obesity among adults aged $\geq 35$ years between 1993 and 2003, and to evaluate their association with diabetes, hypertension and HDC in England.

\section{Methods}

\section{Study population}

The HSE is a large, cross-sectional nationwide survey carried out annually in a representative sample of the non-institutionalised English population. The annual household response rate is around $73 \%$. This study presents data from adults aged $\geq 35$ years only (the age group mostly at risk for CVD). Ninety-four per cent of the sample was of self-defined 'white' ethnic group. In total, 24742 people aged $\geq 35$ years with valid height, weight and WC data were identified in the annual surveys over the period 1993 to 2003. The risks of diabetes, hypertension and HDC associated with generalised and abdominal adiposity are presented for the years 1994,
1998 and 2003 and refer to individuals from whom valid anthropometric and blood pressure measurements were obtained (Table 1).

Details of the HSE are presented elsewhere ${ }^{16}$. Briefly, data were collected at two home visits. The interviewer's visit included computer-assisted administration of a questionnaire to collect information on sociodemographic data, risk factors (such as smoking and drinking habits) and medical history including doctor-diagnosed diabetes. At the interview stage (Stage 1), informants had a height measurement taken using standard procedures. Height was measured using a portable stadiometer with a sliding head plate, a base plate and three connecting rods marked with a metric measuring scale. Informants were asked to remove their shoes. One measurement was taken, with the informant stretching to the maximum height and the head positioned in the Frankfort plane. The reading was recorded to the nearest millimetre.

Weight was measured using Soehnle, Seca or Tanita electronic scales with a digital display. Informants were asked to remove shoes and any bulky clothing. A single measurement was recorded to the nearest $100 \mathrm{~g}$. Informants who were chair-bound or unsteady on their feet were not weighed. Height and weight measurement were used to calculate BMI $\left(\mathrm{kg} \mathrm{m}^{-2}\right)$. Generalised obesity was defined as $\mathrm{BMI} \geq 30 \mathrm{~kg} \mathrm{~m}^{-2}$.

Measurements of WC and blood pressure (as well as other physical measurements) were taken by nurses using standardised procedures in a subsequent visit ${ }^{16}$. WC was defined as the midpoint between the lower rib and the upper margin of the iliac crest. It was measured using a tape with an insertion buckle at one end. The measurement was taken twice, using the same tape, and was recorded to the nearest even millimetre. Those whose two waist measurements differed by more than $3 \mathrm{~cm}$ had

Table 1 Sample characteristics by sex and year of survey

\begin{tabular}{|c|c|c|c|c|c|c|}
\hline \multirow[b]{2}{*}{ Characteristic } & \multicolumn{3}{|c|}{ Men } & \multicolumn{3}{|c|}{ Women } \\
\hline & 1994 & 1998 & 2003 & 1994 & 1998 & 2003 \\
\hline$n$ & 4775 & 4980 & 4831 & 5824 & 6079 & 6059 \\
\hline No. of nurse visits & 4214 & 4335 & 3850 & 4993 & 5193 & 4711 \\
\hline Age (years) & $55.2 \pm 13.7$ & $55.6 \pm 13.9$ & $56.0 \pm 13.8$ & $56.9 \pm 14.8$ & $56.6 \pm 14.7$ & $56.7 \pm 14.7$ \\
\hline Diabetes $(\%)^{*}$ & $3.9(3.4-4.5)$ & $4.5(3.9-5.1)$ & $6.4(5.7-7.1)$ & $2.7(2.3-3.1)$ & $3.3(2.9-3.8)$ & $4.6(4.1-5.1)$ \\
\hline Hypertension (\%)* & $44.7(43.2-46.2)$ & $44.6(43.1-46.1)$ & $43.1(41.5-44.7)$ & $44.1(42.7-45.5)$ & $41.3(40.0-42.6)$ & $39.2(37.8-40.6)$ \\
\hline $\operatorname{HDC}(\%)^{\star}$ & $1.9(1.5-2.3)$ & $2.4(2.0-2.8)$ & $3.2(2.7-3.7)$ & $1.4(1.1-1.7)$ & $1.6(1.3-1.9)$ & $1.8(1.5-2.1)$ \\
\hline BMI $\left(\mathrm{kg} \mathrm{m}^{-2}\right)^{*}$ & $26.7 \pm 3.7$ & $27.1 \pm 3.8$ & $27.8 \pm 4.0$ & $26.4 \pm 4.9$ & $26.9 \pm 5.1$ & $27.2 \pm 5.3$ \\
\hline WC $(\mathrm{cm})^{*}$ & $96.1 \pm 8.4$ & $96.3 \pm 8.7$ & $99.0 \pm 9.0$ & $83.6 \pm 9.3$ & $83.6 \pm 10.0$ & $86.9 \pm 10.3$ \\
\hline Never smoked $(\%)^{\star}$ & 32.6 (31.3-33.9) & $30.8(29.5-32.1)$ & $34.5(32.9-36.1)$ & $50.0(48.7-51.3)$ & $44.8(43.6-46.1)$ & $47.6(46.1-49.1)$ \\
\hline Ex-smoker (\%)* & $42.4(41.0-43.8)$ & $45.3(43.9-46.7)$ & $44.0(42.4-45.6)$ & $26.5(25.4-27.6)$ & $31.8(30.6-33.0)$ & $30.6(29.2-32.0)$ \\
\hline Current smoker $(\%)^{*}$ & $25.0(23.8-26.2)$ & $28.8(27.5-30.6)$ & $21.4(20.1-22.8)$ & $23.5(22.4-24.6)$ & $23.4(22.3-24.5)$ & $21.8(20.6-23.1)$ \\
\hline Exceed alcohol limit $(\%)^{\star}$ & $19.6(18.5-20.7)$ & $23.9(22.7-25.1)$ & $42.6(41.2-44.0)$ & $6.3(5.7-6.9)$ & $15.2(14.3-16.1)$ & $25.7(24.6-26.8)$ \\
\hline Physically inactive $(\%)^{*}$ & NA & $41.3(39.9-42.7)$ & $39.2(37.8-40.6)$ & NA & $46.0(44.8-47.3)$ & $45.1(43.9-46.4)$ \\
\hline Manual social class $(\%)^{\star}$ & $53.3(51.9-54.7)$ & $51.2(49.8-52.6)$ & $50.4(49.0-51.8)$ & $40.2(38.9-41.5)$ & $47.6(46.3-48.9)$ & $35.7(34.5-36.9)$ \\
\hline
\end{tabular}

HDC - hypertension-diabetes co-morbidity; BMI - body mass index; WC - waist circumference; NA - not available.

Data are presented as mean \pm standard deviation or frequency ( $95 \%$ confidence interval).

*Age-standardised. 
a third measurement taken. The mean of the two valid measurements was used in the analysis. Informants who reported that they had a colostomy or ileostomy, or were chair-bound, were excluded from the measurement. All those with measurements considered unreliable by the nurse, for example due to excessive clothing or movement, were excluded from the analysis. The definition of raised WC was, in accordance with the report of the National Cholesterol Education Program Adult Treatment Panel (ATP) III $^{17},>102 \mathrm{~cm}$ in men and $>88 \mathrm{~cm}$ in women.

Blood pressure was measured by an oscillometric device, the Dinamap 8100 from 1993 to 2002 and the Omron HEM 907 in 2003. Using an appropriately sized cuff, three sitting blood pressure readings were taken on the right arm after a 5-min rest. Informants who had eaten, drank alcohol or smoked in the $30 \mathrm{~min}$ prior to measurements were excluded from analyses. Data used in this study are based on the mean of the second and third measurements. When comparing blood pressure measurements over time, predicted Omron readings were derived from the Dinamap readings using suitable regression equations ${ }^{3}$, and were used in the analysis. The definition of hypertension was taking of antihypertensive medication or having systolic blood pressure $\geq 140 \mathrm{mmHg}$ or diastolic $\geq 90 \mathrm{mmHg}$. HDC was defined as the existence of both hypertension and diabetes. Further information on the survey methodology can be found in the HSE report ${ }^{16}$.

\section{Risk factors}

Informants were categorised as 'current cigarette smokers' and 'non-/ex-cigarette smokers'. Alcohol intake was assessed by asking informants about the frequency, quantity and type of alcoholic drink consumed and the amount drunk on the heaviest drinking day in the last seven days. This was used to calculate the number of number of units of alcohol drunk on the heaviest drinking day in the last week. Physical activity was categorised as the number of days (in the past four weeks) on which informants had participated to at least a moderate level of activity, for at least $30 \mathrm{~min}$ a time, in: occupational work, heavy housework, heavy manual/'do it yourself' (DIY), walking - fast/brisk, sport/exercise. Social class was assigned on the basis of occupation of the head of the household (Office of Population Censuses and Surveys, 1991). Social classes were further grouped into manual and non-manual.

\section{Statistical analysis}

Analyses were carried out to look at the trends in obesity and raised WC using the HSE data from 1993 to 2003. The age-standardised prevalence (calculated using the proportion from the mid-year 2003 English population) of adult obesity and raised WC for 1993 to 2003 was analysed for each year separately, by sex. To assess risk of hypertension and/or diabetes associated with different fat patterns, sex-specific logistic regression models were run separately for the different years using data from 1994 , 1998 and 2003, adjusting simultaneously for age, smoking, alcohol intake, social class and physical activity (except for 1994 when these data were not collected). Data were analysed using STATA 8.0.

\section{Non-response weighting}

Non-response weighting was introduced in the HSE for the first time in 2003. When data from 2003 are analysed, the estimates are presented weighted for non-response to improve the precision of surveys estimates. However, non-response weights are not available for previous HSE datasets (1993-2002). Logistic regression analyses of the 1994 and 1998 data were not weighted for non-response. To analyse trends over time for obesity, raised WC, hypertension and diabetes, unweighted data have been used. This practice has become standard protocol to ensure that, when analysing trends over time, the prevalence and estimates are comparable.

\section{Results}

The age-standardised prevalence of generalised obesity increased among men from $15.8 \%$ in 1993 to $26.3 \%$ in 2003 , and among women from $19.3 \%$ to $25.8 \%$ (Fig. 1). The prevalence increased in both sexes but more rapidly among men, so that in recent years there has been little difference between the sexes in generalised obesity

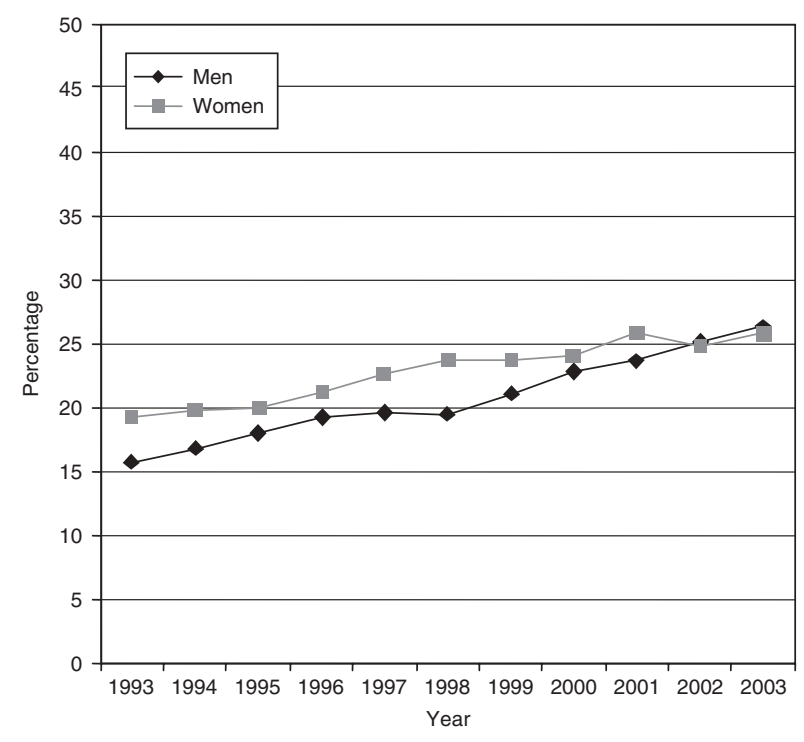

Fig. 1 Trends in generalised obesity (body mass index $\geq 30 \mathrm{~kg} \mathrm{~m}^{-2}$ ) in men and women aged 35 years and over: England, 1993-2003 


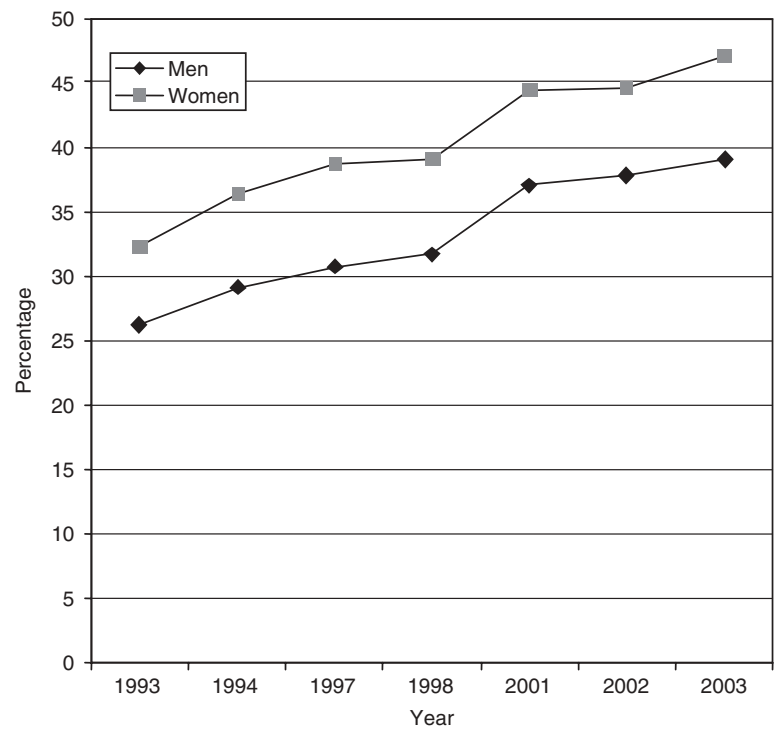

Fig. 2 Trends in abdominal obesity (raised waist circumference: $>102 \mathrm{~cm}$ in men and $>88 \mathrm{~cm}$ in women) in men and women aged 35 years and over: England, 1993-2003

prevalence. Abdominal obesity increased from 26.2\% in 1993 to $39.0 \%$ (men) in 2003; and from 32.4\% to $47.0 \%$ (women) (Fig. 2). Women always showed higher rates than men, but the prevalence rates increased to the same extent in both sexes.

The age-standardised prevalence of self-reported diabetes increased in men from $3.9 \%$ in 1994 to $4.5 \%$ in 1998 and $6.4 \%$ in 2003 and in women from $2.7 \%$ to $3.3 \%$ and $4.6 \%$, respectively. The prevalence of hypertension showed a (non-significant) decrease in men and women between 1994, 1998 and 2003. Age-standardised prevalence of hypertension in men was $44.7 \%$ in $1994,44.6 \%$ in 1998 and 43.1\% in 2003; and in women 44.1\%, 41.3\% and $39.2 \%$, respectively (Table 1 ). The above analyses included both treated and untreated hypertensive individuals. We carried out the analyses excluding those who were treated to examine whether this would affect the trends in prevalence of hypertension, and found that this did not change the results significantly (data not shown).

In 1994, 1998 and 2003 generalised and abdominal obesity were independently associated with risk of hypertension, diabetes and HDC. For example, among men, the odds for diabetes associated with generalised obesity, after adjusting for possible confounders, were 1.24, 1.82 and 2.10 in 1994, 1998 and 2003, respectively. The odds for women were 1.62 in 1994, 2.26 in 1998 and 2.62 in 2003. Similar results were observed for hypertension and HDC (Tables 2a-c). Abdominal obesity similarly predicted these conditions in both sexes (Tables 2a-c).

The results presented so far have not taken into account that generalised and abdominal obesity are related, i.e. that many people who have $\mathrm{BMI} \geq 30 \mathrm{~kg} \mathrm{~m}^{-2}$ may also have raised WC. Therefore further analyses were
Table 2a OR $(95 \% \mathrm{Cl})^{\star}$ for diabetes in men and women aged 35 years and over with $\mathrm{BMI} \geq 30 \mathrm{~kg} \mathrm{~m}^{-2}$ and raised $\mathrm{WC}(>102 \mathrm{~cm}$ in men and $>88 \mathrm{~cm}$ in women)

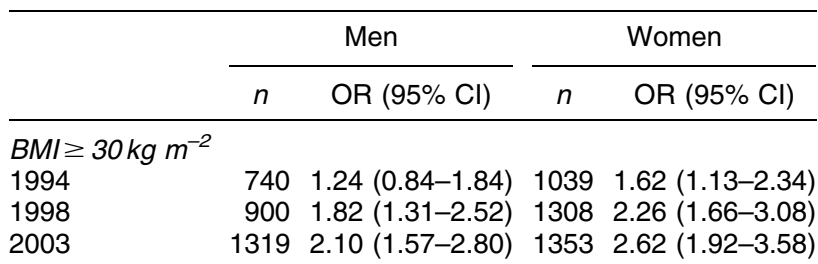

Raised WC

1994

1998

2003

$1211 \quad 1.48(1.06-2.06) 1714 \quad 3.15(2.08-4.79)$

$13021.91(1.41-2.59) 18892.71(1.93-3.79)$

$14911.68(1.26-2.24) 21302.83(1.99-4.03)$

OR - odds ratio; $\mathrm{Cl}$ - confidence interval; $\mathrm{BMI}$ - body mass index; WC waist circumference.

*Adjusted for age, social class, alcohol consumption, cigarette smoking and physical activity.

Table 2b OR $(95 \% \mathrm{Cl})^{\star}$ for hypertension in men and women aged 35 years and over with $\mathrm{BMI} \geq 30 \mathrm{~kg} \mathrm{~m}^{-2}$ and raised $\mathrm{WC}(>102 \mathrm{~cm}$ in men and $>88 \mathrm{~cm}$ in women)

\begin{tabular}{|c|c|c|c|c|}
\hline & \multicolumn{2}{|r|}{ Men } & \multicolumn{2}{|r|}{ Women } \\
\hline & $n$ & OR $(95 \% \mathrm{Cl})$ & $n$ & OR $(95 \% \mathrm{Cl})$ \\
\hline \multicolumn{5}{|c|}{$B M I \geq 30 \mathrm{~kg} \mathrm{~m}^{-2}$} \\
\hline 1994 & 617 & $2.10(1.72-2.56)$ & 819 & $2.66(2.20-3.21)$ \\
\hline 1998 & 739 & $2.06(1.71-2.49)$ & 1049 & $2.81(2.37-3.33)$ \\
\hline 2003 & 788 & $2.20(1.83-2.65)$ & 920 & $2.24(1.83-2.74)$ \\
\hline \multicolumn{5}{|c|}{ Raised WC } \\
\hline 1994 & 1123 & $1.99(1.69-2.34)$ & 1596 & $2.18(1.88-2.52)$ \\
\hline 1998 & 1162 & $1.90(1.64-2.21)$ & 1707 & $2.59(2.23-3.01)$ \\
\hline 2003 & 1253 & $1.86(1.58-2.20)$ & 1779 & $2.20(1.87-2.59)$ \\
\hline
\end{tabular}

OR - odds ratio; $\mathrm{Cl}$ - confidence interval; $\mathrm{BMI}$ - body mass index; WC waist circumference.

*Adjusted for age, social class, alcohol consumption, cigarette smoking and physical activity.

Table 2c OR $(95 \% \mathrm{Cl})^{\star}$ for $\mathrm{HDC}$ in men and women aged 35 years and over with $\mathrm{BMI} \geq 30 \mathrm{~kg} \mathrm{~m}^{-2}$ and raised $\mathrm{WC}(>102 \mathrm{~cm}$ in men and $>88 \mathrm{~cm}$ in women)

\begin{tabular}{|c|c|c|c|c|}
\hline & \multicolumn{2}{|r|}{ Men } & \multicolumn{2}{|r|}{ Women } \\
\hline & $n$ & OR $(95 \% \mathrm{Cl})$ & $n$ & OR $(95 \% \mathrm{Cl})$ \\
\hline \multicolumn{5}{|c|}{$B M I \geq 30 \mathrm{~kg} \mathrm{~m}^{-2}$} \\
\hline 1994 & 744 & $1.14(0.69-1.88)$ & 1040 & $2.10(1.32-3.36)$ \\
\hline 1998 & 900 & $2.56(1.66-3.95)$ & 1310 & $2.06(1.34-3.16)$ \\
\hline 2003 & 1139 & $2.62(1.79-3.83)$ & 1353 & $3.02(1.93-4.73)$ \\
\hline \multicolumn{5}{|c|}{ Raised WC } \\
\hline 1994 & 1216 & $1.46(0.97-2.19)$ & 1716 & $5.47(3.02-9.89)$ \\
\hline 1998 & 1302 & $2.06(1.38-3.07)$ & 1890 & $2.51(1.66-3.79)$ \\
\hline 2003 & 1491 & $1.80(1.25-2.59)$ & 2130 & $3.60(2.13-6.09)$ \\
\hline
\end{tabular}

$\mathrm{OR}$ - odds ratio; $\mathrm{Cl}$ - confidence interval; $\mathrm{HDC}$ - hypertension-diabetes co-morbidity; BMI - body mass index; WC - waist circumference.

${ }^{*}$ Adjusted for age, social class, alcohol consumption, cigarette smoking and physical activity.

carried out to separate the two categories to determine if there are differences in the risk of these conditions between those who are obese but have a normal WC and those who have a raised WC but are not obese 
Table 3 OR $(95 \% \mathrm{Cl})^{\star}$ for hypertension, diabetes and HDC in men and women aged 35 years and over with raised WC $(>102 \mathrm{~cm}$ in men and $>88 \mathrm{~cm}$ in women), excluding those with $\mathrm{BMI} \geq 30 \mathrm{~kg} \mathrm{~m}^{-2}$

\begin{tabular}{|c|c|c|c|c|}
\hline & \multicolumn{2}{|r|}{ Men } & \multicolumn{2}{|r|}{ Women } \\
\hline & $n$ & OR $(95 \% \mathrm{Cl})$ & $n$ & OR $(95 \% \mathrm{Cl})$ \\
\hline \multicolumn{5}{|c|}{ Diabetes } \\
\hline 1994 & 571 & $1.37(0.90-2.10)$ & 825 & $3.34(2.07-5.39)$ \\
\hline 1998 & 488 & $1.60(1.08-2.39)$ & 679 & $1.88(1.16-3.04)$ \\
\hline 2003 & 545 & $1.04(0.66-1.65)$ & 887 & $1.88(1.17-3.01)$ \\
\hline \multicolumn{5}{|c|}{ Hypertension } \\
\hline 1994 & 524 & $1.68(1.35-2.09)$ & 769 & $1.52(1.24-1.86)$ \\
\hline 1998 & 437 & $1.62(1.30-2.02)$ & 618 & $1.79(1.42-2.25)$ \\
\hline 2003 & 455 & $1.38(1.09-1.76)$ & 739 & $1.65(1.31-2.06)$ \\
\hline \multicolumn{5}{|l|}{$H D C$} \\
\hline 1994 & 572 & $1.49(0.90-2.45)$ & 825 & $5.74(2.91-11.30)$ \\
\hline 1998 & 488 & $1.41(0.82-2.44)$ & 679 & $1.80(1.01-3.21)$ \\
\hline 2003 & 545 & $0.97(0.52-1.79)$ & 887 & $2.05(1.02-4.13)$ \\
\hline
\end{tabular}

$\mathrm{OR}$ - odds ratio; $\mathrm{Cl}$ - confidence interval; $\mathrm{HDC}$ - hypertension-diabetes co-morbidity; WC - waist circumference; BMI - body mass index.

${ }^{*}$ Adjusted for age, social class, alcohol consumption, cigarette smoking and physical activity.

$\left(\mathrm{BMI}<30 \mathrm{~kg} \mathrm{~m}^{-2}\right)$. The relative odds for diabetes, hypertension and HDC remained similar to those reported above (Table 3).

\section{Discussion}

This large, nationally representative dataset collected in England from 1993 to 2003 shows that the prevalence of generalised obesity is increasing in both sexes. Obesity also represents an increasing problem worldwide; prevalence data from individual national data collated by the IOTF show that generalised obesity has increased by about $10-40 \%$ in a majority of European countries in the past 10 years $^{18}$.

Although BMI provides a measure of overall adiposity, abdominal (central or visceral) fat deposition is generally considered a key component of obesity. There is evidence showing that abdominal obesity is more strongly associated with risk factors for $\mathrm{CVD}^{19,20}$ and is generally a better predictor for future risk of the metabolic syndrome, type 2 diabetes, morbidity ${ }^{21}$ and all-cause mortality than generalised obesity. Our data showed that abdominal obesity (measured using WC) increased by more than 10\% from 1993 to 2003 in men and by about 15\% in women.

In this scenario, it is perhaps surprising that the prevalence of hypertension showed little change in men and women between 1994, 1998 and 2003. Analysing untreated hypertensive individuals separately did not change the results. Therefore, better management through treatment does not explain these results. Other factors, such as higher levels of awareness about high blood pressure and changes in dietary habits (including salt consumption), may be involved.
These large datasets collected in England in 1994, 1998 and 2003 show that both generalised and abdominal obesity are associated with increased risks of diabetes, hypertension and HDC. Another study has also shown that both types of obesity in men and women are associated with increased odds of hypertension (odds ratio $(\mathrm{OR})=1.99$ in white men, 2.83 in women $)^{22}$. By separating the two categories to distinguish whether the risk of diabetes, hypertension and HDC occurs more often in generalised obesity or in abdominal obesity, our findings show that women with abdominal obesity only (without generalised obesity) are at higher risk of diabetes, hypertension and HDC. Abdominal obesity in women was found to be associated with higher levels of blood pressure and insulin resistance in another work ${ }^{23}$. Raised WC in women has also been shown to be a stronger predictor of insulin sensitivity than generalised obesity ${ }^{24}$. In a further study among women intra-abdominal fat accumulation was shown to play an important role in the pathogenesis of hypertension ${ }^{25}$. Others have shown that the risk of mortality caused by coronary heart disease is increased eight times in women with abdominal fat deposition, independent of weight or $\mathrm{BMI}^{26}$. Our findings show that men with abdominal obesity on its own had higher odds of hypertension than those without abdominal obesity (or $\mathrm{BMI} \geq 30 \mathrm{~kg} \mathrm{~m}^{-2}$ ). The Olivetti Heart Study also showed that WC in men was a strong predictor of elevated blood pressure, independent of BMI and insulin resistance ${ }^{27}$.

These results strongly suggest the urgent need for early identification of abdominal obesity. Health-care professionals need to incorporate WC measurements in their routine practice.

This is the first investigation in England using data collected in large, nationally representative samples to show abdominal obesity to be more strongly associated with HDC than generalised obesity, especially in women. These findings are similar to those reported in the USA ${ }^{5}$.

This paper also adds to the epidemiological evidence that abdominal (central deposition of fat or visceral) obesity is more strongly associated with risk factors for CVD than generalised obesity.

The data show a substantial rise in generalised and abdominal obesity in both men and women. The results also show a strong association between obesity, hypertension and diabetes. Therefore if the prevalence of both obesities increases in future years, the risk that the associated co-morbidities will increase further must be considered.

Disruption in energy balance, environmental and social factors have predominant roles in the development of overweight and obesity. Actions need to be implemented to control the epidemic of obesity. The public health White Paper, Choosing Health: Making Healthy Choices Easier $^{28}$, specifies the UK Government's commitments for action on obesity; moreover, Delivering Choosing 
Health: Making Healthier Choices Easier ${ }^{29}$, Choosing a Better Diet: A Consultation on Priorities for a Food and Health Action Plan ${ }^{30}$ and Choosing Activity: A Physical Activity Action Plan ${ }^{31}$ state action that needs to be taken to address obesity at national, regional and local levels. However, at present there is a lack of effective evidence-based intervention for weight management in primary care.

It is of paramount importance that modifiable lifestyle changes are made to control obesity and encourage weight loss among overweight persons, to prevent them becoming obese. Strategies to control obesity and related co-morbidities should include interventions such as lifestyle modifications to aid generalised and abdominal weight loss. There is a substantial body of evidence indicating that weight loss is an effective strategy for reducing risk for hypertension and diabetes, and can lead to clinical benefits and improvements in health ${ }^{17,32-35}$.

The risk of diabetes, hypertension and HDC is closely associated with obesity as we have shown. It is evident that unless behaviour changes aimed at individuals are taken $^{36}$, to slow the increase or reverse the direction of trends in generalised and central obesity ${ }^{9,10}$, there may be a rise in the prevalence of some of these co-morbidities in the future. Primary prevention of obesity, including abdominal obesity, should be a major public health priority.

Limitations of this study are that it is cross-sectional in nature, and therefore the directionality of the associations between diabetes, hypertension, HDC and adiposity cannot be clearly established. However, evidence from other epidemiological studies shows that obesity predicts hypertension and diabetes 5 .

In the 1994, 1998 and 2003 surveys the ORs for diabetes, hypertension and HDC were greater for obese persons and those with raised WC than for persons without these conditions. However, we cannot comment on the trends for these associations because the ORs were obtained separately for each survey year, and the data were not weighted for non-response in 1994 and 1998 as was done for 2003. Moreover, the OR was not adjusted for physical activity in 1994 because such data were not collected in this year.

There is controversy about the best measure in the assessment of abdominal obesity. We used WC measurements rather than waist-hip ratio (WHR) calculations in accordance with the IOTF $^{15}$ and ATP III $^{17}$ recommendations, and also in view of the lack of consensus about appropriate WHR levels and what thresholds should be used to define raised $\mathrm{WHR}^{20}$.

\section{Conclusion}

Both generalised and abdominal obesity rates continue to increase in adults in England. Because of this increase it can be expected that the risk of some associated co-morbidities will also increase in the future. The consistent independent association between obesity, diabetes, hypertension and associated cardiovascular co-morbidities seen in this nationally representative study is alarming. In order to tackle these issues there is an urgent need to improve the treatment of obesity through effective, evidence-based, weight management interventions for individuals and health professionals.

\section{Acknowledgements}

Sources of funding: The Health Surveys for England on which this paper is based are funded by the Department of Health. The authors are currently funded by the NHS Information Centre to work on subsequent Health Surveys for England. The views expressed are those of the authors, not of the funders.

Conflict of interest declaration: None declared.

Authorship responsibilities: P.P. and V.H. initiated the idea of the paper. P.Z. carried out the statistical analysis. P.P. and V.H. interpreted and reviewed the results. V.H. drafted initial and subsequent versions of the manuscript. The funding body played no role in the formulation of the design, methods, subject recruitment, data collection, analysis or preparation of this paper.

Acknowledgements: We thank all the staff of the Joint Health Surveys Unit at Department of Epidemiology and Public Health (UCL) and National Centre for Social Research (NatCen); the participants in the survey; and Mary Pierce, Jennifer Mindell and Meena Kumari for their helpful comments on an earlier version of this paper.

\section{References}

1 World Health Organization. Obesity and overweight [online], 2006. Available at http://www.who.int/dietphysicalactivity/ publications/facts/obesity/en/. Accessed 20 September 2006.

2 Department of Health. Health Survey for England - trend data [online], undated. Available at http://www.ic.nhs. uk/statistics-and-data-collections/health-and-lifestyles/healthsurvey-for-england. Accessed August 2007.

3 Sproston K, Primatesta P, eds. Health Survey for England 2003. London: The Stationery Office, 2004.

4 Jonsson S, Hedblad B, Engstrom G, Nilsson P, Berglund G, Janzon L. Influence of obesity on cardiovascular risk. Twenty-three-year follow-up of 22,025 men from an urban Swedish population. International Journal of Obesity and Related Metabolic Disorders 2002; 8: 1046-53.

5 Okosun IS, Chandra KM, Choi S, Christman J, Dever GE, Prewitt TE. Hypertension and type 2 diabetes co-morbidity in adults in the United States: risk of overall and regional adiposity. Obesity Research 2001; 9: 1-9.

6 Weir MR. Diabetes and hypertension: blood pressure control and consequences. American Journal of Hypertension 1999; 12: 170S-8S.

7 Huang Z, Willett WC, Manson JE, Rosner B, Stampfer MJ, Speizer FE, et al. Body weight, weight change, and risk for 
hypertension in women. Annals of Internal Medicine 1998; 128: 81-8.

8 Epstein M, Sowers JR. Diabetes mellitus and hypertension. Hypertension 1992; 19: 403-18.

9 Kopelman PG. Obesity as a medical problem. Nature 2000; 404: 635-43.

10 Gensini GF, Comeglio M, Colella A. Classical risk factors and emerging elements in the risk profile for coronary artery disease. European Heart Journal 1998; 19(Suppl. A): A53-61.

11 Garrow J. Body composition for the investigation of obesity. Basic Life Sciences 1990; 55: 183-90.

12 Stamatelopoulos KS, Lekakis JP, Vamvakou G, Katsichti P, Protogerou A, Revela I, et al. The relative impact of different measures of adiposity on markers of early atherosclerosis. International Journal of Cardiology 2007; 119: 139-46.

13 International Diabetes Federation (IDF). IDF consensus worldwide definition of the metabolic syndrome [online], 2006. Available at http://www.idf.org/webdata/docs/IDF. Accessed 10 September 2006.

14 Eckel RH, Grundy SM, Zimmet PZ. The metabolic syndrome. Lancet 2005; 365: 1415-28.

15 International Obesity Task Force. About Obesity [online], June 2007. Available at http://www.iotf.org/aboutobesity. asp. Accessed August 2007.

16 Department of Health. Health Survey for England (HSE) 2003. Methodology and documentation report [online], 2004. Available at http://www.archive2.officialdocuments. co.uk/document/deps/doh/survey03/md/md.htm. Accessed 10 May 2006.

17 National Institutes of Health (NIH). Third Report of the National Cholesterol Education Program Expert Panel on Detection, Evaluation and Treatment of High Blood Cholesterol in Adults (Adult Treatment Panel III). NIH Publication 01-3670. Bethesda, MD: NIH, 2001.

18 Rossner S. Obesity: the disease of the twenty-first century. International Journal of Obesity and Related Metabolic Disorders 2002; 26(Suppl. 4): S2-4.

19 Walker SP, Rimm EB, Ascherio A, Kawachi I, Stampfer MJ, Willett WC. Body size and fat distribution as predictors of stroke among US men. American Journal of Epidemiology 1996; 144: 1143-50.

20 Molarius A, Seidell JC. Selection of anthropometric indicators for classification of abdominal fatness - a critical review. International Journal of Obesity and Related Metabolic Disorders 1998; 22: 719-27.

21 Sjostrom L. Obesity and its relationship to other diseases. In: Shetty PS, McPherson K, eds. Diet, Nutrition and Chronic Disease: Lessons from Contrasting Worlds. LSHTM Sixth Annual Public Health Forum. London: Wiley, 1996; 235-9.

22 Harris MM, Stevens J, Thomas N, Schreiner P, Folsom AR. Associations of fat distribution and obesity with hypertension in a bi-ethnic population: the ARIC study. Atherosclerosis Risk in Communities Study. Obesity Research 2000; 8: $516-24$
23 Faria AN, Ribeiro Filho FF, Gouveia Ferreira SR, Zanella MT. Impact of visceral fat on blood pressure and insulin sensitivity in hypertensive obese women. Obesity Research 2002; 10: 1203-6.

24 Carey D, Jenkins AB, Campbell LV, Freund J, Chisholm DJ. Abdominal fat and insulin resistance in normal and overweight women: direct measures reveal a strong relationship in subjects at both low and high risk of NIDDM. Diabetes 1996; 45: 633-8.

25 Kanai H, Matsuzawa Y, Kotani K, Keno Y, Kobatake T, Nagai $\mathrm{Y}$, et al. Close correlation of intra-abdominal fat accumulation to hypertension in obese women. Hypertension 1990; 16: 484-90.

26 Manson JE, Willett WC, Stampfer MJ, Colditz GA, Hunter DJ, Hankinson SE, et al. Body weight and mortality among women. New England Journal of Medicine 1995; 333: 677-85.

27 Siani A, Cappuccio FP, Barba G, Trevisan M, Farinaro E, Lacone R, et al. The relationship of waist circumference to blood pressure: the Olivetti Heart Study. American Journal of Hypertension 2002; 15: 780-6.

28 Department of Health. Choosing Health: Making Healthy Choices Easier [online], 2004. Available at http:// www.dh.gov.uk/en/Publicationsandstatistics/Publications/ PublicationsPolicyAndGuidance/DH_4094550. Accessed 10 July 2006.

29 Department of Health. Delivering Choosing Health: Making Healthier Choices Easier [online], 2005. Available at http:// www.dh.gov.uk/assetRoot/04/10/57/13/04105713.pdf. Accessed 10 September 2006.

30 Department of Health. Choosing a Better Diet: A Consultation on Priorities for a Food and Health Action Plan [online], 2003. Available at http://www.dh.gov.uk/asset Root/04/06/58/34/04065834.pdf. Accessed 10 September 2006.

31 Department of Health. Choosing Activity: A Physical Activity Action Plan [online], 2005. Available at http://www.dh. gov.uk/assetRoot/04/10/57/10/04105710.pdf. Accessed 10 July 2006.

32 Pi-Sunyer FX. Short-term medical benefits and adverse effects of weight loss. Annals of Internal Medicine 1993; 119: 722-6.

33 Huang Z, Reddy A. Weight change, ideal weight and hypertension. Current Opinions in Nephrology and Hypertension 1999; 8: 343-6.

34 Staessen J, Fagard R, Lijnen P, Amery A. Body weight, sodium intake, and blood pressure. Journal of Hypertension 1989; 7(Suppl.): S19-23.

35 Broom J. Systematic review of the long-term effects and economic consequences of treatments for obesity and implications for health improvement. The Research Findings Register [online], 2004. Available at http://www. ReFeR.nhs.uk/ViewRecord.asp?ID=1274. Accessed 15 July 2006.

36 Hill JO, Wyatt HR, Reed GW, Peters JC. Obesity and the environment: where do we go from here? Science 2003; 299: $853-5$. 